See discussions, stats, and author profiles for this publication at: https://www.researchgate.net/publication/334684753

\title{
Towards a design framework for the structural systems of tall buildings that considers embodied greenhouse gas emissions
}

Conference Paper · July 2019

CITATIONS

0

3 authors:

2. James Helal

University of Melbourne

6 PUBLICATIONS 28 CITATIONS

SEE PROFILE

Robert H Crawford

University of Melbourne

151 PUBLICATIONS 2,448 CITATIONS

SEE PROFILE
READS

34

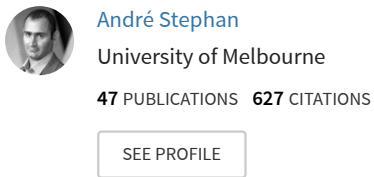

Some of the authors of this publication are also working on these related projects:

Hybrid life cycle inventory of Chilean construction materials View project

Towards a design framework for the structural systems of tall buildings that considers embodied environmental flows View project 


\title{
Towards a design framework for the structural systems of tall buildings that considers embodied greenhouse gas emissions
}

\author{
J. Helal, A. Stephan \& R.H. Crawford \\ University of Melbourne, Parkville, Australia
}

\begin{abstract}
During the 1960s, the Bangladeshi-American structural engineer and architect Fazlur Rahman Khan proposed an influential design framework for the structural systems of tall buildings titled premium-for-height. Khan argued that the challenge of a structural engineer is to design structural systems that minimise the increase in structural material weight per gross floor area with increasing building height. However, in meeting the challenges of climate change and urbanisation, minimising the embodied environmental flows of tall buildings must also be a priority in structural design frameworks. This paper proposes to expand the premium-for-height framework for tall buildings by considering the embodied greenhouse gas emissions of structural systems using a hybrid life cycle inventory analysis method. Advanced structural analysis and a comprehensive consideration of building parameters are also proposed. To demonstrate the use and potential of the framework, embodied greenhouse gas emissions of six case study tall buildings are analysed. The results are discussed and recommendations are made to improve the reliability of the more comprehensive framework.
\end{abstract}

\section{INTRODUCTION}

In its most recent special report titled 'Global Warming of $1.5^{\circ} \mathrm{C}$ ', the Intergovernmental Panel on Climate Change (IPCC) (2018) asserted that drastic changes are required by governments, industries and societies to limit global warming to $1.5^{\circ} \mathrm{C}$ above pre-industrial levels. To meet this target, global anthropogenic greenhouse gas (GHG) emissions, the most significant driver of climate change, must be reduced by at least $49 \%$ of 2017 levels by 2030 (IPCC, 2018). Rapid and far-reaching transitions in the building construction industry, which is responsible for $23 \%$ of global anthropogenic GHG emissions (Huang et al., 2018), are required to mitigate the effects of climate change.

Regulations and current attempts to improve the environmental performance of buildings have principally focused on operational energy. However, studies have revealed that the growing significance of embodied environmental flows in buildings is often underestimated (Dixit, 2017). Moreover, improvements in the operational efficiency of buildings is often achieved using assemblies of high embodied energy such as thermal insulation and advanced façade systems. Therefore, as the operational energy efficiency of buildings improves and their operational GHG emissions decreases, embodied GHG emissions (EGHGE) will progressively form a higher proportion of the life cycle environmental flows of buildings (Säynäjoki et al., 2012, Stephan et al., 2013).

The growing density in urban areas has resulted in an increased reliance on tall buildings globally, whereby the total number of buildings taller than $200 \mathrm{~m}$ increased by $400 \%$ from 2000 to 2017 (from 263 to 1,319) (CTBUH, 2017). The number and average height of tall buildings are expected to continue growing as a means of avoiding urban sprawl and establishing more compact cities that are attributed with less car dependency, better public transport services and better health outcomes (Roo and Miller, 2000, Stevenson et al., 2016).

The construction of tall buildings generates a high spatial and temporal concentration of GHG emissions, a phenomenon described by Säynäjoki et al. (2012) as a 'carbon spike.' Emissions of GHGs have an enduring impact on global warming with their effects lasting over a century in the case of nitrous oxide $\left(\mathrm{N}_{2} \mathrm{O}\right)$ and hundreds of thousands of years for carbon dioxide $\left(\mathrm{CO}_{2}\right)$ (IPCC, 
2018). These 'carbon spikes' are exacerbated in the case of tall buildings that can have up to $60 \%$ more embodied energy per gross floor area (GFA) than low rise buildings (Treloar et al., 2001). This increase in resource use with increasing building height, termed by Khan (1967) as the premium-for-height, is mainly due to the cumulative effect of wind and earthquake loads on the structural systems of tall buildings.

Several studies have explored the relationship between structural systems and the embodied environmental flows of tall buildings. A study by Cho et al. (2012) analysed four alternative steel structural systems for the design of a 35 -storey tall building and compared them according to their embodied energy. As is common in studies of this nature, the structural systems were deemed to be equivalent via a lateral deflection limit against static wind loading and their embodied energy was quantified using a process-based life cycle inventory (LCI) analysis. The study found that the use of a braced frame structural system can result in a $21 \%$ reduction in embodied energy compared to a rigid frame. A study by Foraboschi et al. (2014) assessed the embodied energy of structural systems for tall buildings ranging in height from 20 to 70 stories composed of a reinforced concrete (RC) shear wall and either an RC rigid frame or a steel rigid frame. By also using a process-based LCI analysis and an equivalent lateral deflection limit, the study concluded that RC rigid frames can result in up to $44 \%$ less embodied energy per GFA than that of steel frames for certain tall buildings. The results of existing studies clearly show the importance of the type of structural system in the reduction of embodied environmental flows for tall buildings. However, the reviewed studies universally use structural analysis techniques that can be unacceptably conservative in the design of tall buildings, such as the static treatment of wind loading (Mendis et al., 2007). These studies also universally adopt a process-based LCI analysis, which has been shown to suffer from systemic incompleteness and typically underestimates environmental flows by a factor of up to four compared to hybrid approaches (Crawford et al., 2018). Additionally, existing studies neglect the effects of various building parameters (e.g. inter-storey height, floor shape, etc.) that have been shown to have a significant influence on the material quantities of structural systems (Taranath, 2017).

Therefore, in meeting the challenges of climate change and higher density, there is a need to develop structural design frameworks for tall buildings that minimise EGHGE using advanced structural analysis techniques and comprehensive methods for quantifying environmental flows while considering a variety of building parameters.

\subsection{Aim and scope}

The aim of this paper is to propose a design framework for the structural systems of tall buildings that considers their embodied GHG emissions (EGHGE) to assist with early stage design.

Structural systems of tall buildings are designed to perform their intended function throughout their design working life with minimum maintenance and no structural repair being necessary. Consequently, the recurring environmental flows of structural systems are considered negligible. Additionally, the environmental flows involved in the end-of-life stage of buildings are not considered by this study due to it typically representing less than $1 \%$ of their total energy requirement (Winistorfer et al., 2007) and due to the large uncertainties about the demolition/deconstruction processes decades into the future. As such, this work focuses on the EGHGE of structural systems as Zhao and Haojia (2015) have shown that they represent the greatest portion of the life cycle GHG emissions of tall buildings, even when underestimated due to the use of process-based data.

\subsection{Notions and definitions}

This section presents the notions and definitions associated with tall buildings that have been adopted in the framework presented in Section 3.

\subsubsection{Tall buildings}

Among multiple possible definitions, this work adopts the definition for tall buildings proposed by Stafford Smith and Coull (1991) coupled with a minimum height criterion. As such, this work defines a tall building as a building with a height of at least $35 \mathrm{~m}$ and a structural design which is significantly influenced, because of its height, by lateral forces due to wind or earthquake actions. 


\subsubsection{Structural systems}

A structural system is an arrangement of structural elements (e.g. columns, beams, walls and slabs) capable of resisting loads. Tall buildings are generally composed of three structural sub-systems: a lateral load resisting system (LLRS), which predominantly resists wind and earthquake loads, a vertical load resisting system (VLRS), which predominantly resists gravity loads, and a foundation system, which transfers all of the loads to the ground (Ali and Moon, 2018). Due to the high influence of lateral loads on the structural design of tall buildings, this paper classifies structural systems of tall buildings based on their lateral load-resisting systems. Twelve structural systems for tall buildings were identified by this study, including shear wall, outrigger and belt, framed tube and diagrid.

\section{PREMIUM-FOR-HEIGHT FRAMEWORK}

During the 1960s, the Bangladeshi-American structural engineer and architect Fazlur Rahman Khan (1967) proposed a design framework for the structural systems of tall buildings titled premium-for-height. As illustrated in Figure 1, Khan (1967) proposed that the design of tall buildings could be divided into two phases. The first phase involves designing a rigid frame for gravity loads without considering the effects of lateral loads, whereby columns, beams and slabs are proportioned to carry the vertical loads only. As such, the first phase sets the lower boundary of the total quantity of material weight per GFA. All factors affecting the structural design of the tall building are considered in the second phase, including the effects of wind and earthquake loads, leading to an increase in the size of columns or beams or both in the rigid frame. The second phase, therefore, constitutes the upper boundary of material weight per gross floor area (GFA) and establishes the premium-for-height, defined by Khan (1967) as the increase in material weight per GFA with increasing building height. Ultimately, Khan (1967) argued that the challenge of a structural engineer is to design a structural system that minimizes, and possibly eliminates, the premium-for-height for a tall building. This framework is used as the theoretical basis of the extended framework presented in Section 3.

\subsection{Building parameters that affect the premium-for-height framework}

In constructing the premium-for-height framework, the only variable or building parameter that was changed at a time was the number of storeys, while all others were kept constant. However, for the premium-for-height to be used as a practical and reliable structural design framework, the effects of various building parameters must be studied. These building parameters include:

- Aspect ratio: the proportion of the length of the building to its width;

- Height ratio: the proportion of the height of the building to its width;

- Inter-storey height: the floor-to-floor height, typically ranging from $3 \mathrm{~m}$ to $4 \mathrm{~m}$;

- Floor shape: the shape of the floor plan (i.e. rectangular, circular, triangular, etc.);

- Material and section properties, which affect how elements support and resist loads; and

- Influence of wind and earthquake loads, which often govern the design of tall buildings.

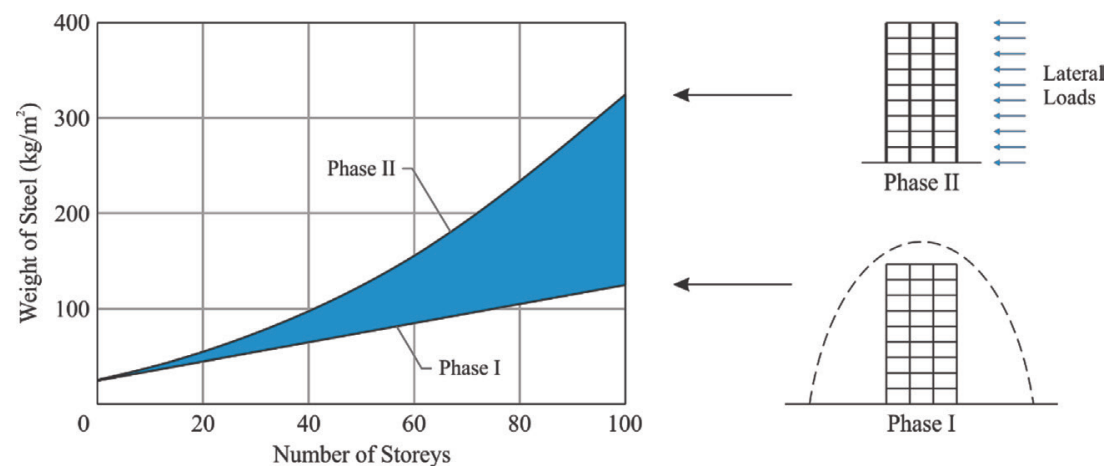

Figure 1. Premium-for-height framework as proposed by Khan (1967). 
The following section presents the method to expand the premium-for-height framework to consider EGHGE of structural systems while accounting for the influence of a range of building parameters.

\section{METHOD}

This section presents the method of constructing the revised premium-for-height framework. The method consists of defining the lower and upper boundaries of various material weights per GFA for rigid frames of different building parameters. The material weight equations are then developed for a range of structural systems. Material weights are converted to EGHGE using a hybrid life cycle inventory analysis method.

\subsection{Material quantities for rigid frames designed to resist vertical loads}

Using a similar method to the premium-for-height framework, the first phase of constructing the revised framework involves varying the building parameters listed in Section 2.1 and designing rigid frames of different structural materials (e.g. reinforced concrete, steel and timber) to resist vertical loads only. A multivariate linear regression would be used to quantify the influence of building parameters on material quantities and develop linear equations that define the lower boundaries of material use for each material.

To ensure that these rigid frames meet the performance criteria related to gravity loads, the structures are modelled and analysed using a Finite Element Method (FEM) for structural analysis. FEM consists of idealising and modelling a building floor by means of discrete elements and nodes with six degrees of freedom being considered at each node. Once all the floors are modelled, a stiffness matrix and an applied gravity load vector are generated. The system of equations is solved and the displacements and stresses at all the nodes are obtained to ensure that the rigid frames meet performance requirements.

Material quantities per GFA are then extracted from the models and a multivariate linear regression is undertaken to quantify the influence of building parameters on material quantities. The following equation for each material would result from the regression analysis:

$$
Q_{m}=b_{0, m}+b_{1, m} x_{1}+b_{2, m} x_{2}+\cdots+b_{p, m} x_{p}
$$

where Q $m=$ quantity of structural material $m$ per GFA (e.g. $150 \mathrm{~kg} / \mathrm{m} 2$ of steel); $b 0, m=$ quantity of structural material $m$ per GFA when all building parameter values are equal to zero (e.g. $35 \mathrm{~kg} /$ $\mathrm{m} 2$ of steel); $b 1, m$ through $b p, m=$ regression coefficients of building parameters for structural material $m$; and $x l$ through $x p=$ value of building parameters (e.g. 5.6 for height ratio).

\subsection{Material quantities for rigid frames and other structural systems designed to resist vertical and lateral loads}

The second phase of constructing the revised framework involves varying building parameters to design rigid frames to resist both vertical and lateral loads using FEM. Maintaining structural equivalency across the rigid frames is critical to ensure that a regression analysis yields reliable polynomial equations that define the upper material boundaries for various structural materials.

Structural equivalency would be established by constraining both lateral displacements and accelerations to acceptable serviceability levels in response to dynamic lateral loads. Acceptable lateral displacements are adopted to limit damage to non-structural components, such as façade, partitions and interior finishes. A commonly used lateral displacement limit is adopted and expressed by the following equation:

$$
\Delta_{l}=\frac{H_{\max }}{500}
$$

where $\Delta_{1}=$ Lateral displacement limit in response to a 1 in 25 -year wind or earthquake event in $\mathrm{mm}$; and $H_{\max }=$ Maximum inter-storey drift in $\mathrm{mm}$.

Acceptable accelerations are also adopted to reduce the effects of motion perceptibility by the users of buildings. An internationally accepted standard for motion perception in tall building design does not exist yet. However, research has shown that accelerations within $0.05 \mathrm{~m} / \mathrm{s}^{2}$ cannot 
be perceived by most people (Mendis et al., 2007). Thus, a $0.05 \mathrm{~m} / \mathrm{s}^{2}$ acceleration limit is adopted in response to a 1 in 25-year wind or earthquake event, analysed dynamically.

Material quantities per GFA are then extracted from the modelled rigid frames and a multivariate second order polynomial regression is conducted to model the curvature of the upper boundary of material quantities for different structural materials. While this technique can be extended for more variables, the following equation would result from a regression with two variables:

$$
Q_{m}=b_{0, m}+b_{1, m} x_{1}+b_{2, m} x_{2}+b_{11, m} x_{1}^{2}+b_{22, m} x_{2}^{2}+b_{12, m} x_{1} x_{2}
$$

where $b_{11, m}$ and $b_{22, m}=$ regression coefficients of second order building parameters for structural material $\mathrm{m}$; and $b_{12, \mathrm{~m}}=$ interaction coefficient between building parameters 1 and 2 . All other variables are the same as in Equation 1.

The same regression method would then be applied to various structural systems of different parameters to yield a comprehensive family of equations that describe material use per GFA.

\subsection{Quantifying the embodied GHG emissions of structural systems per GFA}

The family of equations for material use would be converted to EGHGE per GFA using coefficients obtained through the Path Exchange method for hybridisation, which has been shown to be the most comprehensive life cycle inventory analysis method (Crawford et al., 2018). Developed by Treloar (1997), this hybrid method combines industrial data with average economic data. EGHGE are calculated by multiplying the quantity of materials by their relevant coefficients. EGHGE related to non-physical flows, such as supporting services, are added using an input-output approach by multiplying the price of the material by the GHG emissions per dollar value for the economic sector to which it belongs. The EGHGE of structural systems is calculated as follows:

$$
\begin{aligned}
E G H G E_{S S} & =\sum_{m=1}^{M}\left(Q_{m, S S} \times G F A \times G H G E C_{m}\right) \\
& +\left(T G H G E R T B-\sum_{m=1}^{M} T^{M} H H G E R_{m, S S}-\sum_{m=1}^{M} N A T G H G E R_{m, S S}\right) \times C_{s S}
\end{aligned}
$$

where $E G H G E_{s s}=$ Embodied GHG emissions of structural system $S S$ in $\mathrm{kgCO}_{2}$-e; $Q_{m, S S}=$ Quantity of material $m$ per GFA in the structural system $S S$ as obtained in Equations 2 and 3 (e.g. steel in $\left.\mathrm{kg} / \mathrm{m}^{2}\right) ; G F A=$ gross floor area of the building in $m^{2} ; G H G E C_{m}=\mathrm{GHG}$ emissions coefficient of material $m$ (e.g. $2.86 \mathrm{kgCO}_{2}$-e/ $/ \mathrm{kg}$ for steel); TGHGERTB = Total $\mathrm{GHG}$ emissions requirement of the tall building sector in $\mathrm{kgCO}_{2}$-e per currency unit; TGHGER ${ }_{m, S S}=$ Total GHG emissions requirement of the input-output pathway representing material $m$ in the structural system $S S$ in $\mathrm{kgCO}_{2}$-e/ currency unit; NATGHGER $_{m, S S}=$ Total GHG emissions requirement of all input-output pathways in the tall building sector that are not associated with the material $m$ in the structural system $S S$; and $\mathrm{C}_{\mathrm{ss}}=$ Cost of the structural system $S S$ in currency unit.

\subsection{Constructing the envelope of all possible embodied GHG emissions per GFA}

The method outlined in Section 3.1 to 3.3 yields a family of equations for the EGHGE per GFA of structural systems for various materials and building parameters. The envelope of the equations, which is the curve that is tangential to each member of the family, is then plotted by finding the global maximum and minimum values. This envelope defines the lower and upper boundaries of all possible EGHGE per GFA for any given tall building structural system.

\section{CASE STUDY TALL BUILDINGS}

In order to evaluate the EGHGE of structural systems for tall buildings and demonstrate the use of the proposed framework, three RC and three composite (COMP) tall buildings located in South Korea are analysed. The buildings were constructed between 2002 and 2004 and range from 46 to 
Table 1. Main characteristics of the tall building case studies in South Korea

\begin{tabular}{|c|c|c|c|c|c|c|}
\hline \multirow{2}{*}{ Building Parameter } & \multicolumn{6}{|c|}{ Building Reference } \\
\hline & SHI & $\mathrm{SH} 2$ & $\mathrm{SHOl}$ & SHO2 & $\mathrm{SHO} 3$ & $\mathrm{SHO} 4$ \\
\hline Storeys & 46 & 50 & 51 & 55 & 66 & 73 \\
\hline Height (m) & 148.4 & 173 & 157.4 & 191.1 & 233.8 & 263.7 \\
\hline Gross floor area $\left(\mathrm{m}^{2}\right)$ & 46,901 & 82,384 & 53,186 & 129,870 & 120,210 & 160,929 \\
\hline Floor shape & . & - & 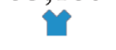 & 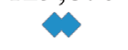 & 口 & $\Delta$ \\
\hline Perimeter (m) & 163.3 & 133 & 162 & 171 & 154 & 258 \\
\hline Height ratio & 3.62 & 3.49 & 3.84 & 4.38 & 6.68 & 5.17 \\
\hline Aspect ratio & 1.05 & 1.15 & 1.00 & 1.70 & 1.20 & 1.25 \\
\hline Lateral load influence & Low & Low & High & Low & Low & Low \\
\hline Structural material & $\mathrm{RC}^{\mathrm{a}}$ & $\mathrm{RC}^{\mathrm{a}}$ & $\mathrm{RC}^{\mathrm{a}}$ & $\mathrm{COMP}^{\mathrm{b}}$ & $\mathrm{COMP}^{\mathrm{b}}$ & $\mathrm{COMP}^{\mathrm{b}}$ \\
\hline Structural system & $\square^{c}$ & $\square^{c}$ & 国 ${ }^{\mathrm{d}}$ & 国 $^{\mathrm{d}}$ & 圖 $^{\mathrm{d}}$ & 国 $^{\mathrm{d}}$ \\
\hline
\end{tabular}

Note: ${ }^{\mathrm{a}}$ reinforced concrete; ${ }^{\mathrm{b}}$ composite; ${ }^{\mathrm{c}} \mathrm{\square}$ shear wall; ${ }^{\mathrm{d}}$ 国 shear wall + outrigger and belt

73 storeys tall. Five of the case study buildings are in the city of Seoul and one is in Busan. The bills of structural material quantities for the structural systems were published by Cho et al. (2004) and complemented by this study with various additional building parameters as presented in Table 1 . The entire dataset is made available on figshare: doi.org/10.26188/5bd5c405c6833.

To understand the effects of various building parameters, one building parameter was altered for each case study building to yield the following hypothetical scenarios:

- SH1*: number of stories of SH1 was increased;

- $\mathrm{SH}_{2} *$ : structural system of SH2 was changed from shear wall to framed tube;

- SHO1*: wind load on SHO1 was increased;

- $\mathrm{SHO} 2 *$ : aspect ratio of $\mathrm{SHO} 2$ was decreased;

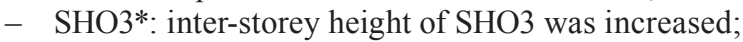

- SHO4*: the shape of SHO4 was changed from triangular to rectangular.

The EGHGE associated with structural materials are calculated by multiplying their quantities with the corresponding hybrid coefficients, which are constructed by combining process data from the Australian Life Cycle Inventory database (AusLCI) (Grant, 2016), environmentally-extended input-output data derived from the input-output tables published by the Australian Bureau of Statistics (ABS) (2018) and GHG emission data from the Australian National Greenhouse Gas Inventory (DEE, 2015). Accordingly, the following EGHGE hybrid coefficients were used in this study: $499.39 \mathrm{kgCO}_{2}-\mathrm{e} / \mathrm{m}^{3}$ for $40 \mathrm{MPa}$ concrete, $2.86 \mathrm{kgCO}_{2}$-e $/ \mathrm{kg}$ for hot rolled steel and $2.39 \mathrm{kgCO}_{2}$-e $/ \mathrm{kg}$ for steel reinforcement. The EGHGE associated with related services were not considered because the aim of this study is not detailed accuracy but rather to demonstrate how the framework can inform decision making. The results are presented in the following section.

\section{RESULTS}

This section presents the calculated EGHGE per GFA of the case study tall buildings and the hypothetical scenarios. The results are summarised in Figure 2 on the following page and explored in this section. Figures 2.i to 2.vi depict the EGHGE per GFA specific to each of the six case study buildings along with their corresponding hypothetical scenarios. Figure 2.vii consolidates the results within the envelope for the EGHGE per GFA of structural systems for various materials and building parameters. The results portrayed in Figure 2.vii show that there is a positive correlation between the number of storeys and EGHGE per GFA of structural systems. However, the different parameters across the analysed structural systems obscure the quantification of the true premium-for-height. 


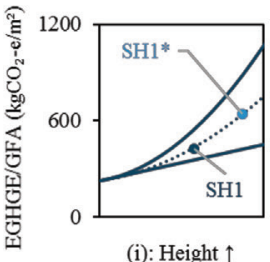

(i): Height $\uparrow$

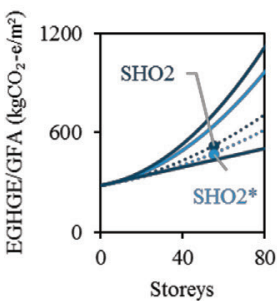

(iv): Aspect ratio $\downarrow$

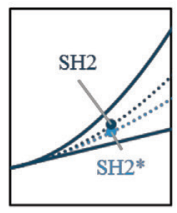

(ii): System change

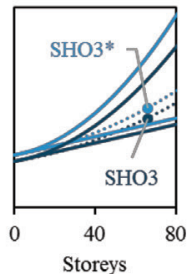

(v): Inter-storey height $\uparrow$

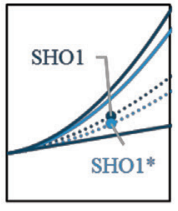

(iii): Wind Load $\downarrow$

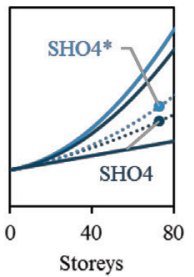

(vi): Shape change

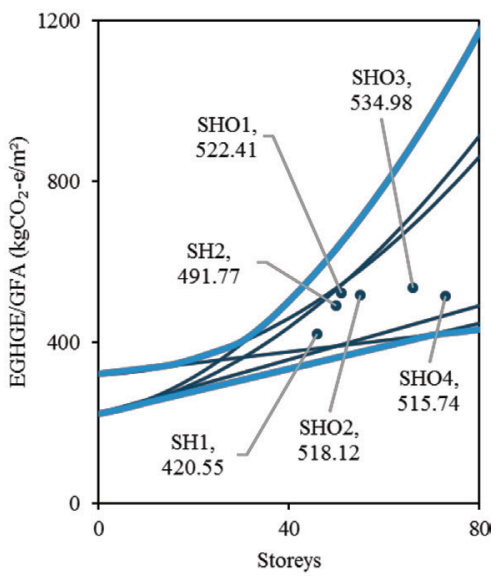

(vii)

: Case study tall building

: Hypothetical scenario

(solid line): Lower or upper boundary curve

(dotted line): Building specific curve

Figure 2. Embodied GHG emissions per GFA for case study buildings and hypothetical scenarios.

As seen in Figure 2.i, the increase in the number of stories from 46 in SH1 to 70 in SH1* would lead to the increase of EGHGE per GFA along the established equation for the shear wall structural system. However, in altering the structural system of SH2 from a shear wall to a framed tube in $\mathrm{SH}_{2}$, the EGHGE per GFA of SH2*, as seen in Figure 2.ii, would drop and follow a different curve within the same boundaries. Figure 2.iii shows that decreasing the intensity of lateral loads on $\mathrm{SHO1}^{*}$, which has the same geometric and material properties as SHO1, would lead to a drop in EGHGE per GFA along a lower curve within a lowered upper boundary. A similar phenomenon would also be observed with a decrease in aspect ratio from $\mathrm{SHO} 2$ to $\mathrm{SHO}_{2}^{*}$, as seen in Figure 2.iv. Both boundaries and EGHGE per GFA curves would be elevated in Figure 2.v when an increase in inter-storey height occurs from $\mathrm{SHO} 3$ to SHO3*. Finally, a change in plan configuration, from triangular in SHO4 to rectangular in SHO4*, would lead to a less efficient configuration, which would translate to a higher EGHGE per GFA curve within a higher upper boundary, as seen in Figure 2.vi. These results indicate the influence of a variety of building parameters on the overall EGHGE per GFA of structural systems and associated curves.

\section{DISCUSSION AND CONCLUSION}

The selection of a functional unit is critical for the reliability of the revised premium-for-height design framework. This study established EGHGE per GFA as the functional unit, and by doing so, omitted building users and their behaviours from the framework. Of all the analysed case study tall buildings, $\mathrm{SHO} 3$ was the only building with readily available data on maximum occupancy (1628 people). Thus, the EGHGE per capita for $\mathrm{SHO} 3$ was found to be $39,502.09 \mathrm{kgCO}_{2}-\mathrm{e} / \mathrm{m}^{2}$. Providing EGHGE per capita enables a comparison of buildings with different layouts and identifying designs that are efficient for humans, not just from a structural design and technical perspective (Stephan and Crawford, 2016).

The proposed framework has the potential to identify components within a structural system which would yield the most savings in EGHGE if optimised. For example, despite only constituting $6 \%$ of the volume of concrete in SH1, steel reinforcement constitutes $41.26 \%$ of the total EGHGE for the structural system. Such knowledge, which could not be derived from the conventional premium-for-height framework by Khan (1967), is crucial for the improvement of the environmental performance of tall buildings during early stage design. 
In mitigating the effects of climate change and urbanisation, design frameworks for the structural systems of tall buildings must consider their environmental effects. As such, this study proposes to expand the influential premium-for-height framework by considering the EGHGE of structural systems in tall buildings. A method to construct the revised premium-for-height framework was presented and its potential exhibited with the analysis of six case study tall buildings.

Future research comprises the development of this comprehensive design framework, which has the potential to assist structural engineers and consultants in selecting and designing structural systems while minimising their effect on the environment.

\section{REFERENCES}

ABS. 2018. 5209.0.55.001 - Australian national accounts: input-output tables, 2014-15. Australian Bureau of Statistics. Canberra, Australia.

Ali, M. \& Moon, K. 2018. Advances in structural systems for tall buildings: emerging developments for contemporary urban giants. Buildings, 8, 104.

Cho, H.-W., Roh, S.-G., Byon, Y.-M. \& Yom, K.-S. 2004. Structural quantity analysis of tall buildings. CTBUH 2004 Seoul Conference. Seoul, South Korea, CTBUH.

Cho, Y.S., Kim, J. H., Hong, S. U. \& Kim, Y. 2012. LCA application in the optimum design of high rise steel structures. Renewable and Sustainable Energy Reviews, 16, 3146-3153.

Crawford, R., Bontinck, P.-A., Stephan, A., Wiedmann, T. \& Yu, M. 2018. Hybrid life cycle inventory methods - A review. Journal of Cleaner Production, 172, 1273-1288.

CTBUH. 2017. Tall buildings in numbers - vertical transportation: ascent \& acceleration. CTBUH Journal, 52-53.

DEE. 2015. National greenhouse gas inventory - Kyoto Protocol classifications. Department of the Environment and Energy. Canberra, Australia.

Dixit, M.K. 2017. Life cycle embodied energy analysis of residential buildings: A review of literature to investigate embodied energy parameters. Renewable and Sustainable Energy Reviews, 79, 390-413.

Foraboschi, P., Mercanzin, M. \& Trabucco, D. 2014. Sustainable structural design of tall buildings based on embodied energy. Energy and Buildings, 68, 254-269.

Grant, T. 2016. AusLCI database manual v1.26. Melbourne, Australia, Australian Life Cycle Assessment Society (ALCAS).

Huang, L., Krigsvoll, G., Johansen, F., Liu, Y. \& Zhang, X. 2018. Carbon emission of global construction sector. Renewable and Sustainable Energy Reviews, 81, 1906-1916.

IPCC. 2018. Global Warming of $1.5^{\circ} \mathrm{C}$. Geneva, Switzerland, Intergovernmental Panel on Climate Change.

Khan, F.R. 1967. Current trends in concrete high-rise buildings. Symposium on Tall Buildings with Particular Reference to Shear Wall Structures. Southampton, England.

Mendis, P., Ngo, T., Haritos, N., Hira, A., Samali, B. \& Cheung, J. 2007. Wind loading on tall buildings. Electronic Journal of Structural Engineering, 7, 41-54.

Roo, G.D. \& Miller, D. 2000. Compact cities and sustainable urban development: a critical assessment of policies and plans from an international perspective, Burlington, VT.

Säynäjoki, A., Heinonen, J. \& Junnila, S. 2012. A scenario analysis of the life cycle greenhouse gas emissions of a new residential area. Environmental Research Letters, 7, 034037.

Stafford Smith, B. \& Coull, A. 1991. Tall building structures: analysis and design, Wiley-Interscience.

Stephan, A. \& Crawford, R.H. 2016. The relationship between house size and life cycle energy demand: Implications for energy efficiency regulations for buildings. Energy, 116, 1158-1171.

Stephan, A., Crawford, R.H. \& De Myttenaere, K. 2013. Multi-scale life cycle energy analysis of a low-density suburban neighbourhood in Melbourne, Australia. Building and Environment, 68, 35-49.

Stevenson, M., Thompson, J., De Sá, T.H., Ewing, R., Mohan, D., Mcclure, R., Roberts, I., Tiwari, G., GilesCorti, B. \& Sun, X. 2016. Land use, transport, and population health: estimating the health benefits of compact cities. The Lancet, 388, 2925-2935.

Taranath, B.S. (2017) Tall building design, Boca Raton, CRC Press.

Treloar, G.J., Fay, R., Ilozor, B. \& Love, P.E.D. 2001. An analysis of the embodied energy of office buildings by height. Facilities, 19, 204.

Winistorfer, P., Chen, Z., Lippke, B. \& Stevens, N. 2007. Energy consumption and greenhouse gas emissions related to the use, maintenance, and disposal of a residential structure. Wood and Fiber Science, 37, 128-139.

Zhao, X. \& Haojia, M.A. 2015. Structural system embodied carbon analysis for super tall buildings. Procedia Engineering, 118, 215-222. 